\title{
Drug-Carrying Magnetic Nanocomposite Particles for Potential Drug Delivery Systems
}

\author{
R. Asmatulu, ${ }^{1}$ A. Fakhari, ${ }^{2}$ H. L. Wamocha, ${ }^{1}$ H. Y. Chu, ${ }^{3}$ Y. Y. Chen, ${ }^{3}$ M. M. Eltabey, ${ }^{1,4}$ \\ H. H. Hamdeh, ${ }^{5}$ and J. C. Ho ${ }^{3,5}$ \\ ${ }^{1}$ Department of Mechanical Engineering, Wichita State University, Wichita, KS, USA \\ ${ }^{2}$ Department of Bioengineering, University of KS, Lawrence, KS, USA \\ ${ }^{3}$ Institute of Physics, Academia Sinica, Taipei, Taiwan \\ ${ }^{4}$ Department of Basic Engineering Science, Menoufya University, Shebin, Egypt \\ ${ }^{5}$ Department of Physics, Wichita State University, Wichita, KS, USA
}

Correspondence should be addressed to R. Asmatulu, ramazan.asmatulu@wichita.edu

Received 10 May 2009; Accepted 5 August 2009

Recommended by Sakhrat Khizroev

Drug-carrying magnetic nanocomposite spheres were synthesized using magnetite nanoparticles and poly (D,L-lactide-coglycolide) (PLGA) for the purpose of magnetic targeted drug delivery. Magnetic nanoparticles ( $\sim 13$ nm on average) of magnetite were prepared by a chemical coprecipitation of ferric and ferrous chloride salts in the presence of a strong basic solution (ammonium hydroxide). An oil-in-oil emulsion/solvent evaporation technique was conducted at $7000 \mathrm{rpm}$ and $1.5-2$ hours agitation for the synthesis of nanocomposite spheres. Specifically, PLGA and drug were first dissolved in acetonitrile (oily phase I) and combined with magnetic nanoparticles, then added dropwise into viscous paraffin oil combined with Span 80 (oily phase II). With different contents $(0 \%, 10 \%, 20 \%$, and $25 \%)$ of magnetite, the nanocomposite spheres were evaluated in terms of particle size, morphology, and magnetic properties by using dynamic laser light scattering (DLLS), scanning electron microscopy (SEM), transmission electron microscopy (TEM), and a superconducting quantum interference device (SQUID). The results indicate that nanocomposite spheres $(200 \mathrm{~nm}$ to $1.1 \mu \mathrm{m}$ in diameter) are superparamagnetic above the blocking temperature near $40 \mathrm{~K}$ and their magnetization saturates above 5000 Oe at room temperature.

Copyright ( $) 2009$ R. Asmatulu et al. This is an open access article distributed under the Creative Commons Attribution License, which permits unrestricted use, distribution, and reproduction in any medium, provided the original work is properly cited.

\section{Introduction}

Recently, researchers have been trying to develop targeted therapeutic systems by using external forces, including magnetic fields, ultrasound, electric fields, temperature, light, and mechanical forces to concentrate drugs within tumors [1-4]. In these systems, the drug is localized at a specific targeted area by externally generated forces, and then activated them [5]. Of the type considered, magnetic particles carrying drug molecules are targeted to specific sides of the body by external magnetic fields. Shortly after concentration on targeted region, drug molecules are gradually released, thus improving the therapeutic efficiency of the drugs by lowering the collateral toxic site effects on the healthy cells or tissues [6-9]. Magnetic targeted system with fields generated between 100 and 2500 Oe seems more promising as the basis of a drug localization system due to their effectiveness, lower risk, cost, and practical use, as compared to other systems [10-12].

The three main mechanisms for releasing drug molecules from the polymeric magnetic spheres into a blood vessel or tissue are diffusion, degradation, and swelling followed by diffusion [13, 14]. Diffusion occurs when drug molecules dissolve in bodily fluids around or within the particles and migrate away from the particles. Degradation takes place when the polymer chains hydrolyze into lower molecular weight species, effectively releasing drug molecules that were trapped by the polymer chains. Swelling-controlled release systems are initially dry. When they are placed in the body, they swell to increase inside pressure and porosity, enabling the drug molecules to diffuse from the swollen network. The release of active drug molecules can also be varied over a 


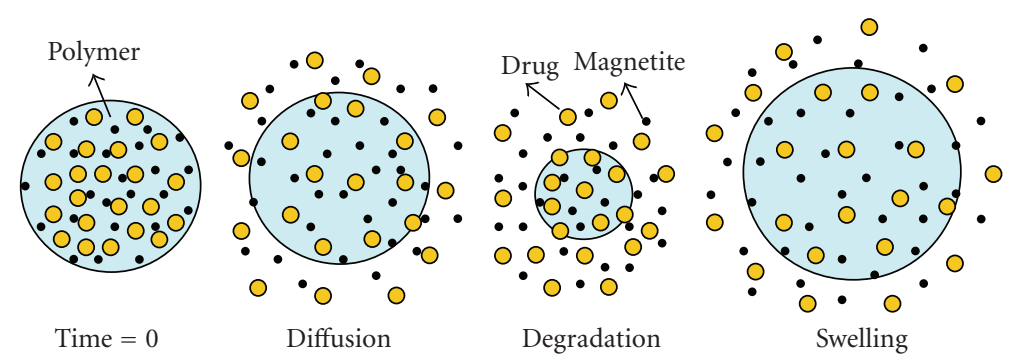

FIGURE 1: Schematic illustrations of diffusion, degradation, and swelling release mechanisms of drug-carrying magnetic PLGA spheres.

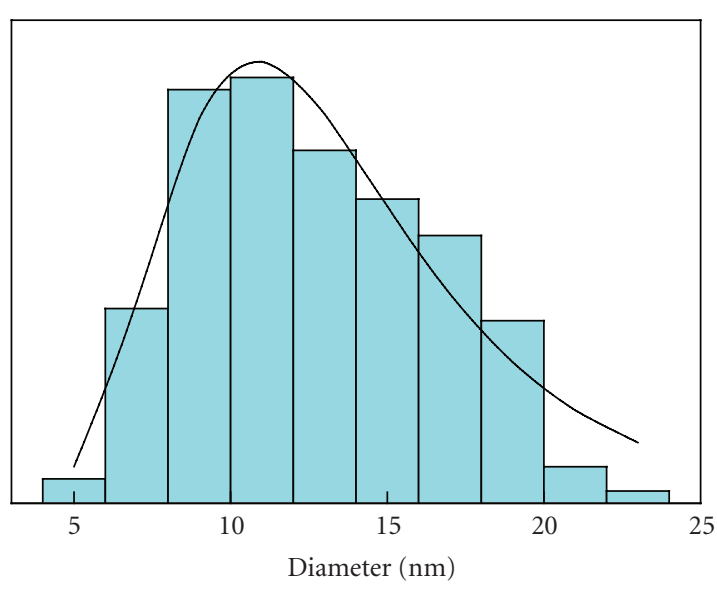

FIGURE 2: Size distribution of magnetic nanoparticles obtained using the TEM images. Solid line is the best fit.

certain period based on external and internal parameters [11-13]. Figure 1 shows the diffusion, degradation, and swelling release mechanisms of drug-carrying magnetic spheres.

Poly (D,L-lactide-co-glycolide) (PLGA), approved by the Food and Drug Administration (FDA) for drug delivery purposes [15-18], is used as a host material because of its biodegradability. In the present research, this polymer was embedded with magnetic nanoparticles (MNPs) and a drug via the oil-in-oil emulsion/solvent evaporation technique [19-22]. MNP concentrations in PLGA were varied in the range of $0 \%$ to $25 \%$. After the fabrication step, biodegradable nanocomposite spheres were characterized to determine the size distribution, morphology, and magnetic properties using dynamic laser light scattering (DLLS), scanning electron microscopy (SEM), transmission electron microscopy (TEM), and a superconducting quantum interference device (SQUID).

\section{Experimental}

2.1. Materials. Unless otherwise specified, all chemicals utilized without further purification or modification in our experiment were reagent grades and purchased from SigmaAldrich.

\subsection{Methods}

2.2.1. Magnetic Nanoparticle Synthesis. Magnetic nanoparticles were prepared using $50 \mathrm{~mL}$ of $2 \mathrm{M} \mathrm{HCl}$ and $55 \mathrm{~mL}$ of $5 \mathrm{M}$ ammonium hydroxide $\left(\mathrm{NH}_{4} \mathrm{OH}\right)$ solutions in a $100 \mathrm{~mL}$ beaker. In separate beakers, $2 \mathrm{~g}$ of ferric chloride $\left(\mathrm{FeCl}_{3} \cdot 6 \mathrm{H}_{2} \mathrm{O}\right)$ was dissolved in $40 \mathrm{~mL}$ of $2 \mathrm{M} \mathrm{HCl}$ and $1.25 \mathrm{~g}$ of ferrous chloride $\left(\mathrm{FeCl}_{2} \cdot 4 \mathrm{H}_{2} \mathrm{O}\right)$ in $10 \mathrm{~mL}$ of $2 \mathrm{M} \mathrm{HCl}$. The two solutions were combined and stirred vigorously at $1200 \mathrm{rpm}$. Then, $55 \mathrm{~mL}$ of $5 \mathrm{M}$ ammonium hydroxide was added in 5 minutes at room temperature. The magnetite nanoparticles with a diameter of $12.7 \mathrm{~nm}$ were then collected using an $\mathrm{Nd}$ magnet and dried in an oven overnight. Figure 2 shows the size distribution of the magnetic nanoparticles obtained using TEM images. ImageJ software was used in the calculations of size distribution.

2.2.2. Magnetic Nanocomposite Spheres Synthesis. In this step, two dissimilar oil phases were prepared. During the first oil phase, $1.25 \% \mathrm{w} / \mathrm{v}$ of PLGA 50 : 50 (wt 40 000-75 000 ) was added to $5 \mathrm{~mL}$ of the solvent (acetonitrile), which was placed in a conical flask with a stopper. The mixture was kept on a hotplate for 20 to 30 minutes to dissolve completely PLGA in acetonitrile using a small magnetic bar. The magnetic bar was removed before known amounts of magnetite nanoparticles and the drug were added to the same solution. Afterwards, the flask was placed in a sonicator for about 10 minutes (or until the MNPs and drug molecules were completely dispersed).

The second oil phase was prepared by adding $1 \% \mathrm{v} / \mathrm{v}$ of Span 80 as a surfactant to $40 \mathrm{~mL}$ of a heavy liquid (paraffin). This mixture was then placed under an overhead mixer operated at $7000 \mathrm{rpm}$ with a specially designed highshear impeller (Figure 3(a)). Note that the shape and size of the impeller is critically important to achieve smallersize nanocomposite spheres. Approximately $3 \mathrm{~mL}$ of the first phase was then added to the second phase using a burette. The mixer was allowed to run for one hour and 30 minutes to evaporate acetonitrile and form nanocomposite spheres in the heavy oil at the high-shear speed. Nanocomposite spheres were collected by centrifugation at $17000 \mathrm{rpm}$ for 30 minutes at $10^{\circ} \mathrm{C}$ and washed four times with $\mathrm{n}$-hexane to completely remove the heavy paraffin liquid. Figure 3(b) shows the schematic illustration of magnetic nanocomposite sphere fabrication. Finally, particles were filtered using a $200 \mathrm{~nm}$ filter media under a $25 \mathrm{inHg}$ vacuum and dried 


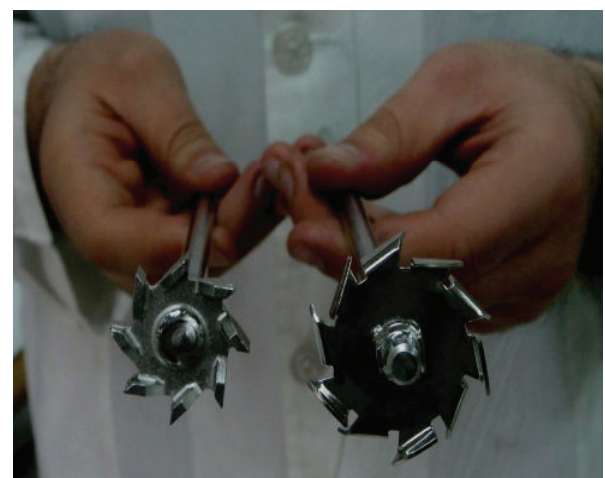

(a)

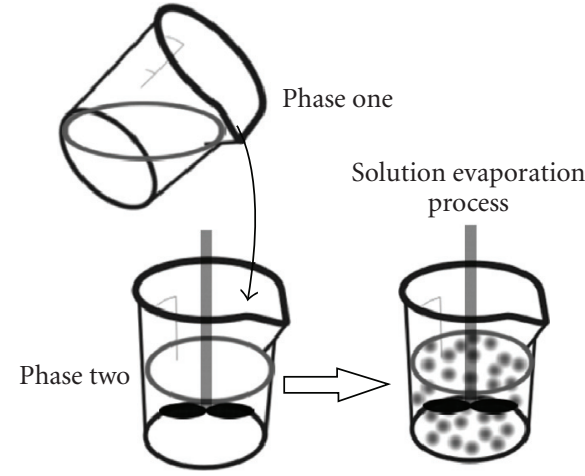

(b)

Figure 3: (a) Specially designed high-shear impellers connected to an overhead high-speed mixer. (b) Sketch of a single oil-in-oil emulsion/solvent evaporation method.

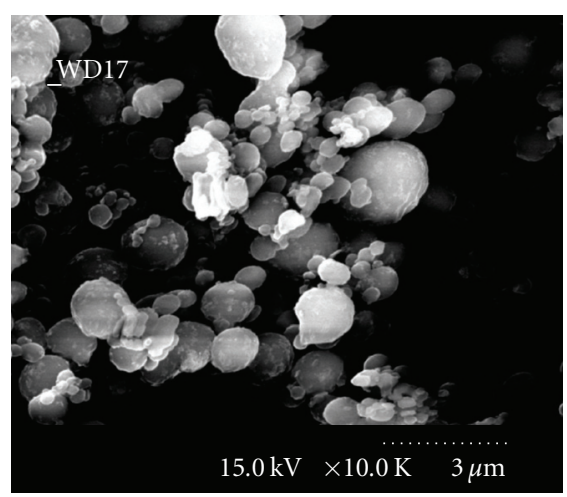

(a)

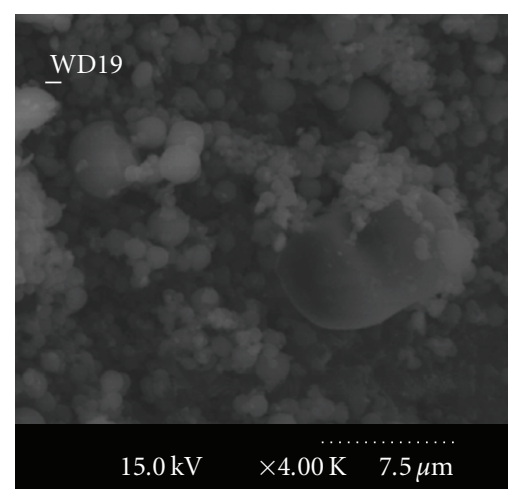

(b)

Figure 4: SEM images showing size and shapes of sample 2 (a) and sample 3 (b).

prior to the SQUID (Quantum Design), DLLS (Malvern Instrument), SEM (Leo1550), and TEM (Joel 2010, $200 \mathrm{kV}$ ) analyses.

\section{Results and Discussion}

Four samples with different MNP and drug contents were prepared to determine the size distribution by DLLS. Table 1 gives the formulation of nanocomposite samples and their size distributions. As the MNP concentration increases from $0 \%$ to $25 \%$, the nanocomposite sphere size increases gradually, as well. This may be due to the viscosity changes, lesser shear forces acting on the spheres, and/or agglomeration of the nanoparticles in the first oil phase.

The samples prepared at each concentration were characterized using SEM. Figure 4 shows the SEM images of samples 2 and 3 containing $10 \%$ and $20 \%$ of magnetite nanoparticles in PLGA, respectively. The nanocomposite spheres are mostly rounded shapes and have a diameter between $200 \mathrm{~nm}$ and $1.1 \mu \mathrm{m}$, which confirms DLLS test results, as indicated in Table 1 . The variation of sphere size and shape in each concentration contributes to the changes in process parameters, viscosity, and heat generated during fabrication [11].

In addition to DLLS and SEM analysis, TEM images (Figure 5) reveal the distribution of magnetic nanoparticles in the drug-carrying nanocomposite spheres. These nanoparticles are randomly oriented in the nanocomposite structure; however, in some areas, the magnetic nanoparticles tend to form clusters, which may be due to the large surface/volume ratio and intermolecular interactions, such as electrostatic, hydrophobic, and van der Waals interactions [14]. Additionally, at high magnification, a crystal lattice is visible in a single magnetite particle, suggesting a singledomain and fully crystalline state.

Magnetic properties of biodegradable nanocomposite spheres were characterized using the SQUID technique. For each sample the magnetization at $300 \mathrm{~K}$ was measured over a range of applied fields between -10000 and +10000 Oe. The data (Figure 6(a)) show that, near 5000 Oe, the magnetization reaches a saturation value roughly proportional to the magnetite content $(10,20$, or $25 \%)$ in the three samples as expected $[11,23]$. In addition to magnetic inclusion, sample 3 also contains $20 \%$ of nonmagnetic drug molecules. 
TABLE 1: Formulation of nanocomposite samples and their size distribution determined by DLLS.

\begin{tabular}{lcccc}
\hline Sample no. & $\begin{array}{c}\text { PLGA } \\
\text { concentration } \\
(\mathrm{w} / \mathrm{v} \%)\end{array}$ & $\begin{array}{c}\text { MNP } \\
\text { concentration } \\
(\mathrm{w} / \mathrm{w} \%)\end{array}$ & $\begin{array}{c}\text { Drug } \\
\text { concentration } \\
(\mathrm{w} / \mathrm{w} \%)\end{array}$ \\
\hline 1 & 1.25 & 0 & 0 & 8 \\
2 & 1.25 & 10 & 0 & 830 \\
3 & 1.25 & 20 & 20 & 1010 \\
4 & 1.25 & 25 & 0 & 1040 \\
\hline
\end{tabular}

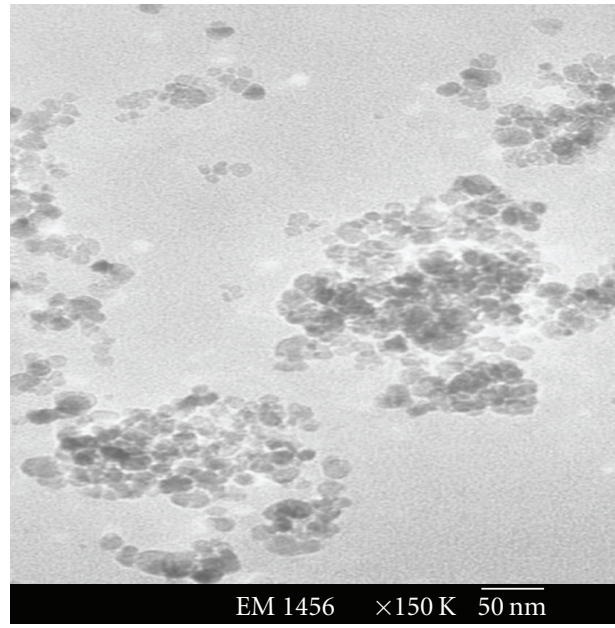

(a)

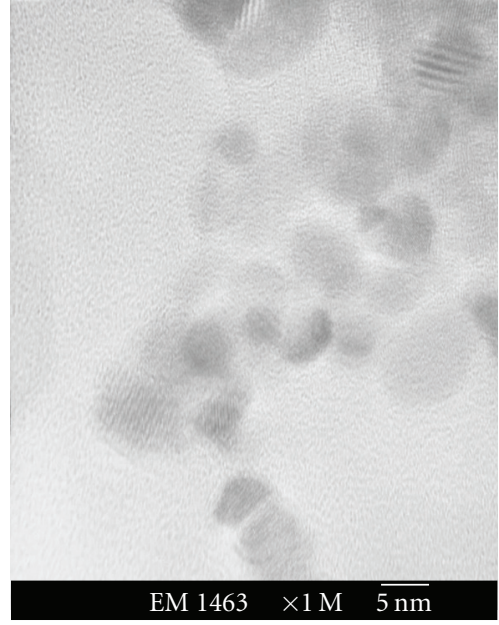

(b)

FIGURE 5: TEM images of drug-carrying nanocomposite spheres showing the distribution of magnetite nanoparticles in PLGA matrix at low (a) and high (b) magnifications.

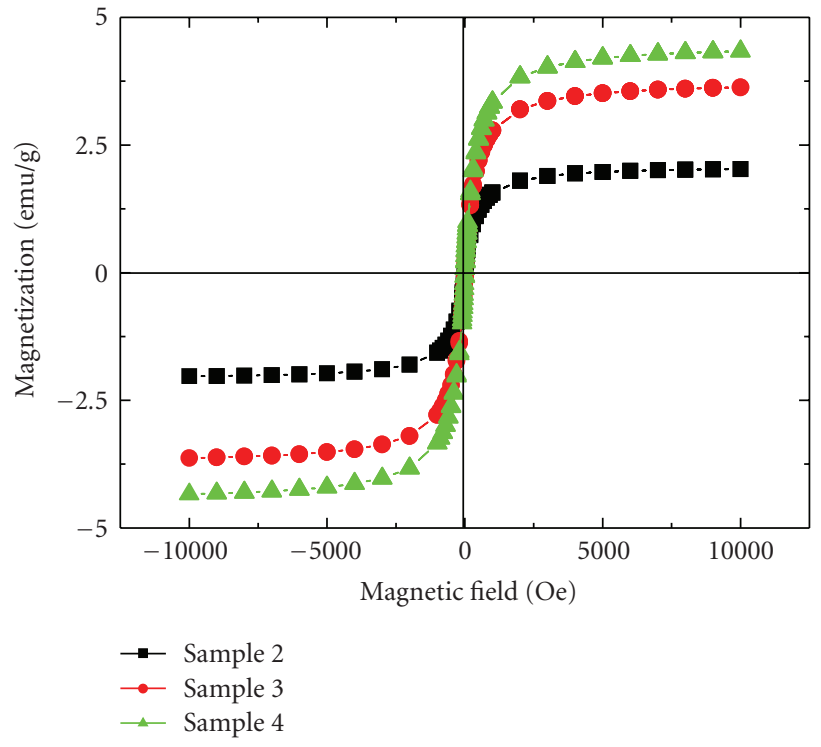

(a)

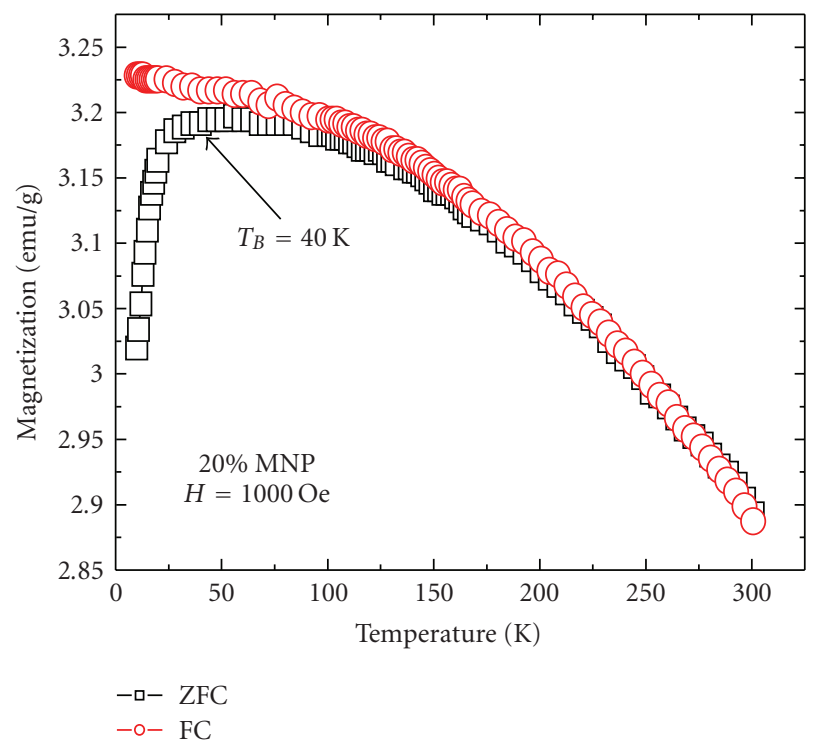

(b)

FIGURE 6: SQUID data of magnetic nanocomposite spheres. (a) Saturation of specific magnetization with an applied field of approximately 5 000 Oe at $300 \mathrm{~K}$. (b) Typical temperature dependence of magnetization, showing a superparamagnetic behavior with a blocking temperature near $40 \mathrm{~K}$. 
Figure 6(b) shows the typical temperature dependence of magnetization for the nanocomposites. The sample 3 was first cooled to the liquid helium temperature near $4 \mathrm{~K}$ before a 1000 -Oe field was applied, and then the sample was heated up in steps to $300 \mathrm{~K}$ for magnetization measurements. As the temperature increases, the magnetization of nanocomposite spheres initially increases to reach a peak at $40 \mathrm{~K}$, beyond which it decreases a paramagnetic-type behavior. This reflects the superparamagnetic characteristics of the nanoparticles, while $40 \mathrm{~K}$ is generally referred to as the blocking temperature [24-26]. Additionally, it is obvious that the merger of the zero field cooled (ZFC) and field cooled (FC) curves starts at about $125 \mathrm{~K}$, and there is a plateau region in ZFC curve. In an earlier study [27] on Dextran-coated magnetite of similar size distribution, a similar blocking temperature was observed but with the two curves merge at a much lower temperature, and the ZFC lacks the features observed in our sample. The magnetite particles of the above mentioned study were evenly dispersed in water based ferrofluid. In contrast, the magnetic particles in our study were randomly separated inside the polymeric nanocomposite spheres. This leads to a distribution of the dipolar interactions among the particles. Knowing that the dipolar interaction energies of these particles are of the same order of their anisotropy energy barriers [28], these energies have significantly contributed to the observed features of the ZFC curve. As a result, the way of mixing the magnetite particles and drug inside the nanocomposite spheres may affect the efficiency of their magnetic delivery system.

\section{Conclusion}

This study deals with the synthesis of drug-carrying magnetic nanocomposite spheres by an oil-in-oil emulsion/solvent evaporation technique. The effect of magnetic particles $(\sim 13 \mathrm{~nm})$ on the size and morphology of the product was determined by DLLS and SEM, which yield a spherical size ranging from $200 \mathrm{~nm}$ to $1.1 \mu \mathrm{m}$. TEM images further revealed magnetite nanoparticles are mostly clustered and randomly distributed in the PLGA matrix. Meanwhile, SQUID data confirmed that the nanocomposite spheres behave as superparamagnetic nanomaterials. Overall, this study may be useful for targeted drug delivery application in the future.

\section{Acknowledgment}

The authors gratefully acknowledge Wichita State University for supporting this work.

\section{References}

[1] C.-K. Kim and S.-J. Lim, "Recent progress in drug delivery systems for anticancer agents," Archives of Pharmacal Research, vol. 25, no. 3, pp. 229-239, 2002.

[2] http://www.cancer.org/docroot/home/index.asp, October 2008.

[3] S. Goodwin, C. Peterson, C. Hoh, and C. Bittner, "Targeting and retention of magnetic targeted carriers (MTCs) enhancing intra-arterial chemotherapy," Journal of Magnetism and Magnetic Materials, vol. 194, no. 1, pp. 132-139, 1999.

[4] S. Sershen and J. West, "Implantable, polymeric systems for modulated drug delivery," Advanced Drug Delivery Reviews, vol. 54, no. 9, pp. 1225-1235, 2002.

[5] A. S. Lübbe, C. Alexiou, and C. Bergemann, "Clinical applications of magnetic drug targeting," Journal of Surgical Research, vol. 95, no. 2, pp. 200-206, 2001.

[6] A. S. Lübbe, C. Bergemann, J. Brock, and D. G. McClure, "Physiological aspects in magnetic drug-targeting," Journal of Magnetism and Magnetic Materials, vol. 194, no. 1, pp. 149155, 1999.

[7] S. R. Rudge, T. L. Kurtz, C. R. Vessely, L. G. Catterall, and D. L. Williamson, "Preparation, characterization, and performance of magnetic iron-carbon composite microparticles for chemotherapy," Biomaterials, vol. 21, no. 14, pp. 1411-1420, 2000.

[8] J. H. Leach, Magnetic targeted drug delivery, M.S. thesis, Virginia Tech Department of Electrical and Computer Engineering, Blacksburg, Va, USA, 2002.

[9] L. A Harris, Polymer stabilized magnetite nanoparticles and poly(propylene oxide) modified styrene-dimethacrylate networks, Ph.D. dissertation, Virginia Tech Department of Chemistry, Blacksburg, Va, USA, 2002.

[10] S.A. Gómez-Lopera, R. C. Plaza, and A. V. Delgado, "Synthesis and characterization of spherical magnetite/biodegradable polymer composite particles," Journal of Colloid and Interface Science, vol. 240, no. 1, pp. 40-47, 2001.

[11] R. Asmatulu, M. A. Zalich, R. O. Claus, and J. S. Riffle, "Synthesis, characterization and targeting of biodegradable magnetic nanocomposite particles by external magnetic fields," Journal of Magnetism and Magnetic Materials, vol. 292, pp. 108-119, 2005.

[12] R. Asmatulu, Biomaterials - Class Notes, Wichita State University, Wichita, Kan, USA, 2008.

[13] http://www.devicelink.com/mpb/archive/97/11/003.html, October 2008.

[14] P. A. R. Glynn, B. M. E. van der Hoff, and P. M. Reilly, "A general model for prediction of molecular weight distributions of degraded polymers, development and comparison with ultrasonic degradation experiments," Journal of Macromolecular Science, Part A, vol. 6, pp. 1653-1664, 1976.

[15] C. N. O'Brien and A. J. Guidry, "Formulation of poly(D,Llactide-co-glycolide) microspheres and their ingestion by bovine leukocytes," Journal of Dairy Science, vol. 79, no. 11, pp. 1954-1959, 1996.

[16] Lima K. M. and J. M. Rodrigues, "Poly(D,L-lactide-coglycolide) microspheres as a controlled release antigen delivery system," Brazilian Journal of Medical and Biological Research, vol. 32, pp. 171-180, 1999.

[17] S.-J. Lee, J.-R. Jeong, S.-C. Shin, et al., "Nanoparticles of magnetic ferric oxides encapsulated with poly(D,L lactideco-glycolide) and their applications to magnetic resonance imaging contrast agent," Journal of Magnetism and Magnetic Materials, vol. 272-276, part 3, pp. 2432-2433, 2004.

[18] J. Emami, H. Hamishehkar, A. R. Najafabadi, et al., "Particle size design of PLGA microspheres for potential pulmonary drug delivery using response surface methodology," Journal of Microencapsulation, vol. 26, no. 1, pp. 1-8, 2009.

[19] B. K. Kim, S. J. Hwang, J. B. Park, and H. J. Park, "Preparation and characterization of drug-loaded polymethacrylate microspheres by an emulsion solvent evaporation method," Journal of Microencapsulation, vol. 19, no. 6, pp. 811-822, 2002. 
[20] R. Asmatulu, A. Fakhari, H. L. Wamocha, H. H. Hamdeh, and J. C. Ho, "Fabrication of magnetic nanocomposite spheres for targeted drug delivery," in Proceedings of ASME International Mechanical Engineering Congress and Exposition (IMECE '08), pp. 1-4, Boston, Mass, USA, November 2008.

[21] A. Santoveña, J. T. García, A. Oliva, M. Llabrés, and J. B. Fariña, "A mathematical model for interpreting in vitro rhGH release from laminar implants," International Journal of Pharmaceutics, vol. 309, no. 1-2, pp. 38-43, 2006.

[22] A. Santoveña, C. Álvarez-Lorenzo, A. Concheiro, M. Llabrés, and J. B. Fariña, "Rheological properties of PLGA film-based implants: correlation with polymer degradation and SPf66 antimalaric synthetic peptide release," Biomaterials, vol. 25, no. 5, pp. 925-931, 2004.

[23] K. H. J. Buschow, Handbook of Magnetic Materials, vol. 16, Elsevier, Amsterdam, The Netherlands, 2006.

[24] H. H. Hamdeh, H. Al-Ghanem, T. J. Folkerts, M. M. Eltabey, J. C. Ho, and R. J. Willey, "Temperature dependent lattice distortion in aerogel-produced Fe-Mo oxides," Applied Physics Letters, vol. 92, no. 24, Article ID 243114, 2008.

[25] R. Asmatulu, R. O. Claus, J. S. Riffle, and M. Zalich, “Targeting magnetic nanoparticles in high magnetic fields for drug delivery purposes," in Proceedings of the Materials Research Society Symposium (MRS '04), vol. 820, pp. 63-68, San Francisco, Calif, USA, April 2004.

[26] Y. Gogotsi, Nanomaterials Handbook, CRC Press, Boca Raton, Fla, USA, 2006.

[27] E. Lima Jr., A. L. Brandl, A. D. Arelaro, and G. F. Goya, "Spin disorder and magnetic anisotropy in $\mathrm{Fe}_{3} \mathrm{O}_{4}$ nanoparticle," Journal of Applied Physics, vol. 99, no. 8, Article ID 083908, 10 pages, 2006.

[28] A. D. Arelaro, A. L. Brandl, E. Lima Jr., et al., "Interparticle interactions and surface contribution to the effective anisotropy in biocompatible iron oxide nanoparticles used for contrast agents," Journal of Applied Physics, vol. 97, no. 10, Article ID 10J316, 3 pages, 2005. 

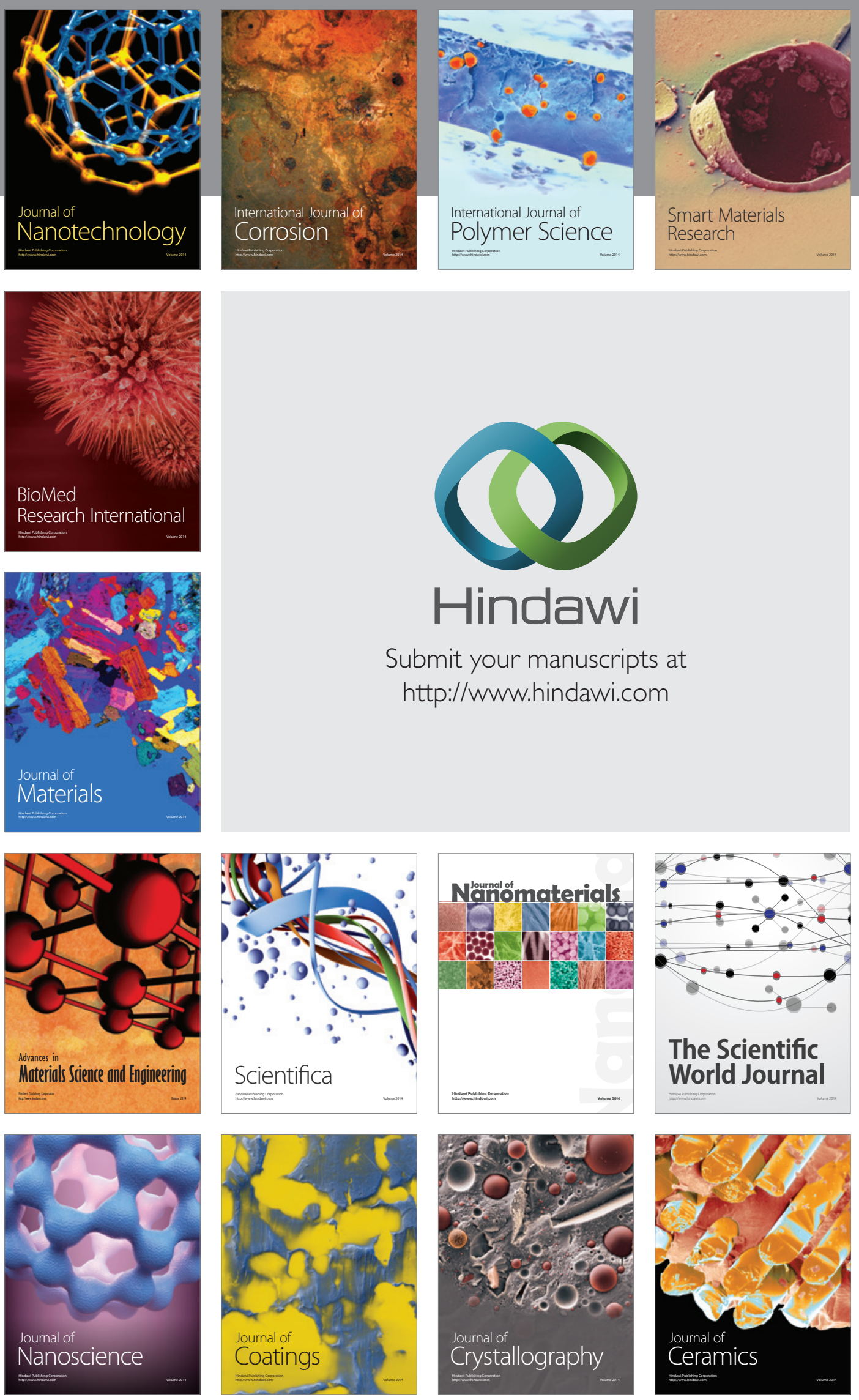

The Scientific World Journal

Submit your manuscripts at

http://www.hindawi.com

\section{World Journal}

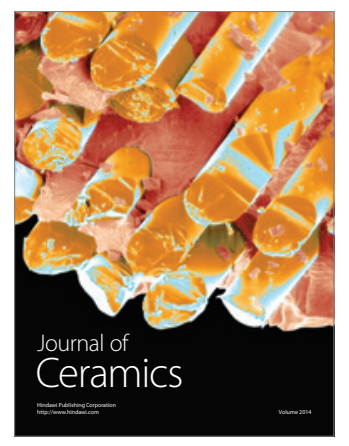

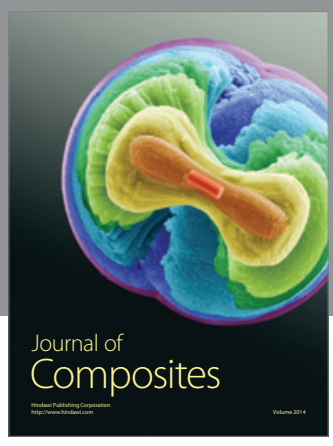
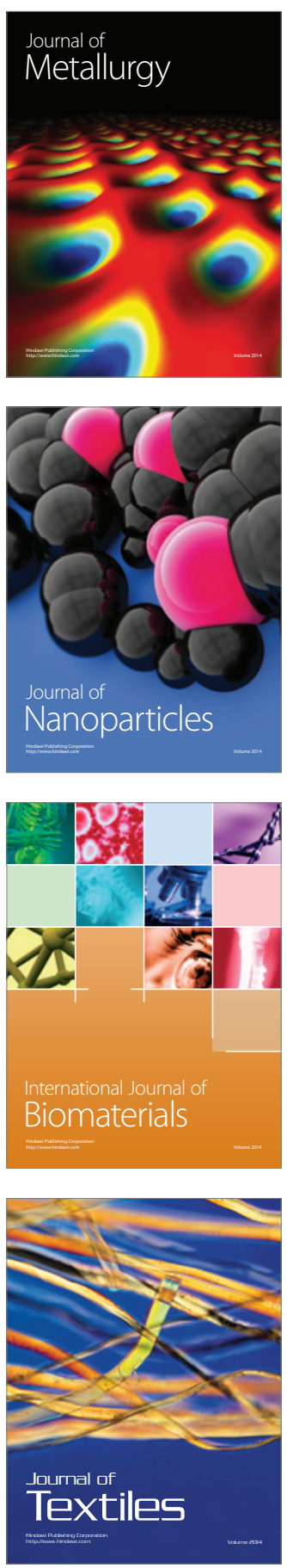